Nordic Concrete Research - Publ. No. NCR 60 - ISSUE 1 / 2019 - Article 8, pp. 131-144

\begin{tabular}{|c|c|}
\hline$\checkmark$ sciendo & 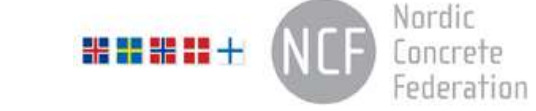 \\
\hline $\begin{array}{l}\text { (C) Article authors. This is an open access article distributed under } \\
\text { the Creative Commons Attribution-NonCommercial-NoDerivs } \\
\text { licens. (http://creaticecommons.org/licenses/by.nc-nd/3.0/). }\end{array}$ & $\begin{array}{l}\text { ISSN online } 2545-2819 \\
\text { ISSN print } \quad 0800-6377\end{array}$ \\
\hline DOI: $10.2478 /$ ncr-2019-0092 & $\begin{array}{r}\text { Received: Sept. 7, } 2018 \\
\text { Revision received: April 17, } 2019 \\
\text { Accepted: June 18, } 2019\end{array}$ \\
\hline
\end{tabular}

\title{
Comparison of Punching Shear Design in Finland According to the Current and the Former Method
}
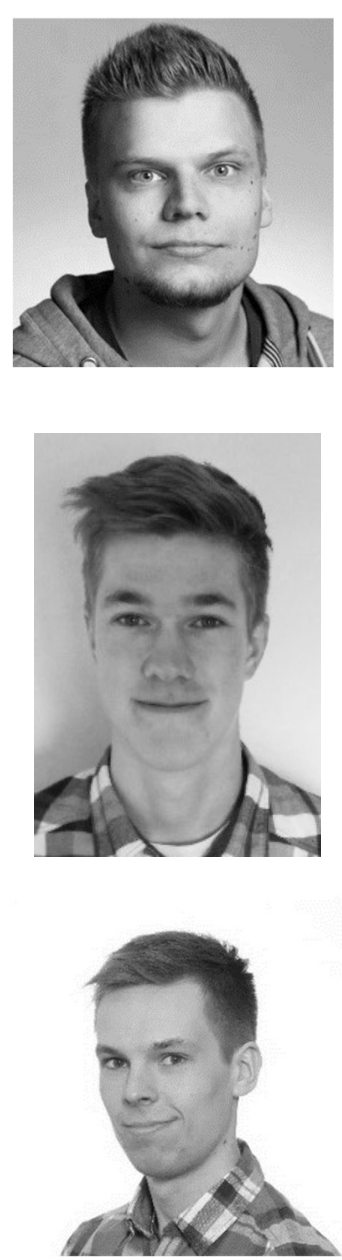

Tuomas Lehtonen

M.Sc.

Specialist, Structural Analysis

Ramboll Finland Oy

Pakkahuoneenaukio 2, FI-33101 Tampere.

(Corresponding author) E-mail: tuomas.lehtonen@ramboll.fi

\section{Matias Hirvikoski}

B.Sc.

M.Sc. student at Tampere University of Technology

Tieteenkatu 18 A95, FI-33720 Tampere.

e-mail: matias.hirvikoski@student.tut.fi

Julius Rajamäki

B.Sc.

M.Sc. student at Tampere University of Technology

Insinöörinkatu 59 B79, FI-33720 Tampere.

e-mail: julius.rajamaki@student.tut.fi

\section{ABSTRACT}

In the beginning of 2017 the design method for punching shear in Finland was changed. The method presented in Eurocode 2 was adopted with some nationally determined parameters and rules. During 2016 and 2017 computational analyses were conducted to compare the previous national design method and the new one. Comparison setups were created in which different 
parameters were varied. The results were presented as line charts. The focus was to find out how the predicted punching resistances differ between the two methods. It was discovered that the differences are significant and can be almost $60 \%$ in some cases.

Key words: Punching, Eurocode, comparison, national annex, structural design.

1.

\section{INTRODUCTION}

1.1

\section{General}

The former national annex (NA) of Finland for Eurocode 2 (EC2) [1] stated that the punching design method in its default form was forbidden due to observed discrepancies between predicted and experimental results. Because of these discrepancies, the NA instructed that the method presented in The National Building Code of Finland (part B4) [2] was to be used instead. This changed in the beginning of 2017 when the new national annexes for Eurocodes were released and the old ones abolished. The new NA for EC2 instructed to use the punching design method of EC2 but with a couple of national rules.

Computational analyses from Ref. [3] and [4] compared these two methods: the former national one and the new EC2-based one. The study aimed to investigate how much they differ, as well as to gain information on the effect of this change on the practical design of concrete structures.

Ref. [5] refers to fib Bulletin 2, Figure 4.4-45 [6] which represents the dependency of the factor $C_{R c}$ and different variables when compared to test results. It discusses that the constant factor for $C_{R c}$ should not be used uniformly because the aforementioned figure shows nonlinear dependency of the punching resistance when the ratio $B / d$ (the ratio between the equivalent diameter and the effective thickness of the slab), as shown in Figure 1. Thus, a revised and non-constant factor for $C_{R c}$ was composed and implemented in the new NA. The bulletin addresses the same issue, as it states that when $B$ is less than about $0.75 d$, basic punching equations should not be used. It also mentions that the CEB-FIB Model Code 90 has an upper limit equation [7] for the punching resistance which is based specifically on this matter. Eurocode 2 Commentary document [8] also discusses the constant coefficient $C_{R c}$ and concludes that the constant factor is correct. However, this document fails to account for the ratio B/d by dealing with the overall resistance based on experimental results rather than isolating the specific effect of this ratio. In literature, this effect is sometimes referred to as the "specific column perimeter $u_{0} / d$ ". It differs from the ratio $B / d$ by the numerator but addresses the same effect - the ratio of the punching column dimensions and the effective thickness of the slab. The B4 method does not directly include this effect in its equations. However, the variable $\beta_{B 4}$ affects the resistance so that when there is eccentricity present, a smaller column periphery results in a smaller resistance, see Equation 11. 


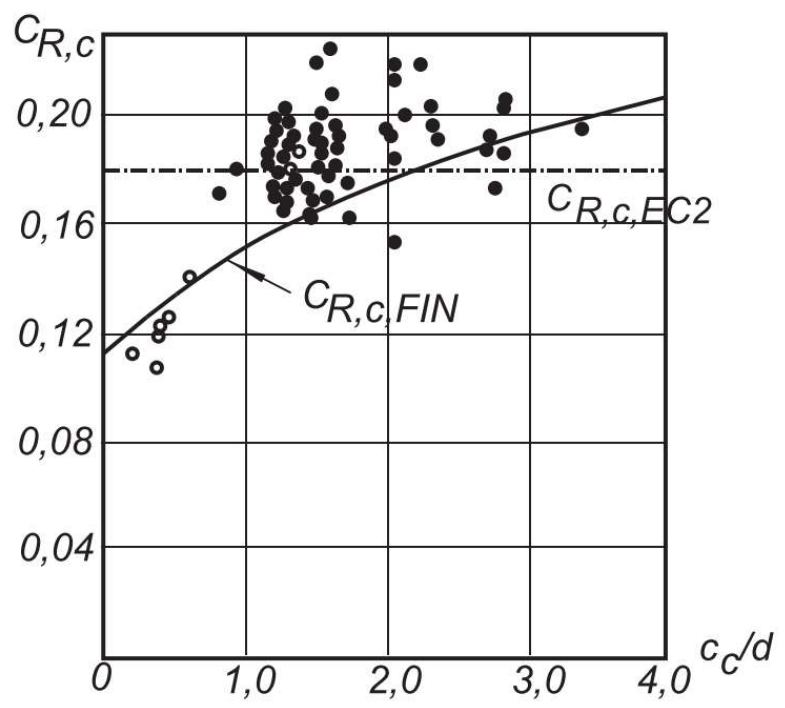

Figure $1-C_{R, c}$ factor compared to experimental values [5].

Finland is not the only country to manipulate the default parameters of EC2 regarding punching shear design. The German National Annex DIN EN 1992-1-1 / NA: 2013-04 also includes a modified set of equations to account for the specific column perimeter $u_{0} / d$. The resulting values for $C_{R c}$ are in good agreement with the ones the Finnish NA propose.

\section{$1.2 \quad$ Description of the design methods}

This section presents the design equations for both methods. It should be emphasized that the basic control perimeters for the two methods differ substantially. In EC2 the basic control perimeter is taken at a distance of $2.0 \mathrm{~d}$ from the loaded area (edge of the column) with rounded corners and in B4 this value is $0.5 \mathrm{~d}$ and with a rectangular shape, see Figure 2.

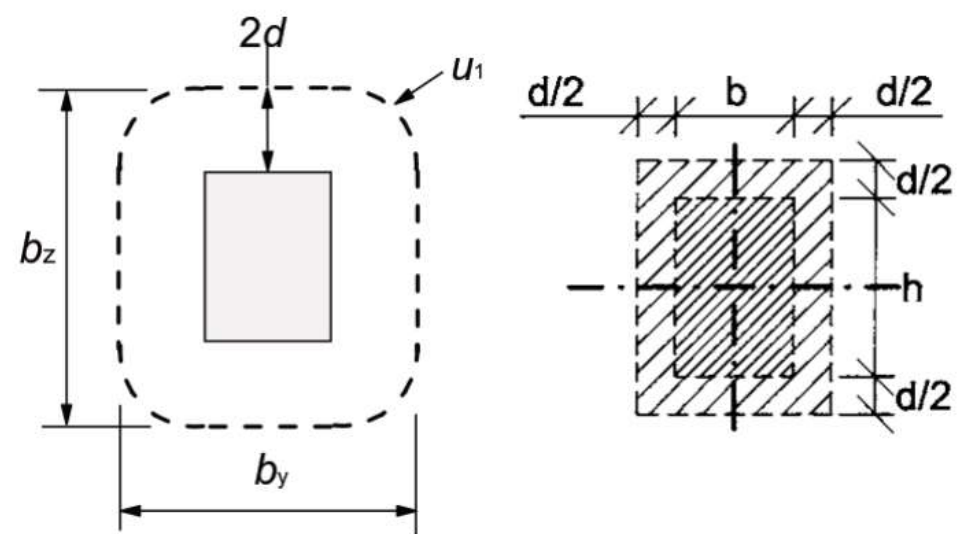

Figure 2-Basic control perimeters according to the compared methods (EC2 left, B4 right) [1,2].

EC2 \& Finnish National Annex (EC2) includes equations for punching resistance without shear reinforcement as follows in Equations 1...6.

$$
V_{R d, c, E C 2}=C_{R d, c} k_{E C 2}\left(100 \rho f_{c k}\right)^{1 / 3} u_{E C} d / \beta_{E C 2}
$$




$$
\begin{aligned}
& C_{R d, c}=\frac{0.3(D / d+1.5)}{\gamma_{c}(D / d+4)} \\
& D=\sqrt{C_{1} C_{2}} \\
& c_{1, c_{2}}=\text { side lengths of the rectangular column } \\
& d=\text { effective thickness of the slab } \\
& k_{E C 2}=1+\sqrt{\frac{200}{d[\mathrm{~mm}]}} \leq 2 \\
& \rho=\frac{A_{s}}{b d} \leq 20 \% 0 \\
& u_{E C 2}=2\left(c_{1}+c_{2}\right)+4 \pi d \\
& \beta_{E C 2}=\text { eccentricity coefficient }
\end{aligned}
$$

For the punching resistance with shear reinforcement, the equations from EC2 are as follows:

$$
V_{R d, c s, E C 2}=\left[\frac{0.75}{4.5} C_{R d, c} k_{E C 2}\left(100 \rho f_{c k}\right)^{\frac{1}{3}}+A_{s w, t o t} f_{y w d, e f}\left(\frac{1}{u_{E C 2} d}\right) \sin (\alpha)\right] u_{E C 2} d / \beta_{E C 2}
$$

$A_{s w, t o t}=$ total shear reinforcement inside an area of $1.5 d$ from the column side

$$
f_{y w d, e f}=250+0.25 d \leq f_{y w d}[\mathrm{MPa}]
$$

The National Building Code of Finland (B4) includes equations for the punching resistance without shear reinforcement as follows in Equations 9...14.

$$
\begin{aligned}
& V_{R d, c, B 4}=k_{B 4} \beta_{B 4}(1+50 \rho) u_{B 4} d f_{c t d} \\
& k_{B 4}=1.6-d[m] \geq 1 \\
& \beta_{B 4}=\frac{0.40}{1+\frac{1.5 e}{\sqrt{A_{u}}}} \\
& \rho=\frac{A_{s}}{b d} \leq 8 \% 0, \\
& e=\text { eccentricity of the punching load } \\
& A_{u}=\text { area inside the control perimeter } \\
& u_{B 4}=2\left(c_{1}+c_{2}\right)+4 d
\end{aligned}
$$

For the punching resistance with shear reinforcement, the equations from B4 are as follows:

$$
\begin{aligned}
& V_{R d, c s, B 4}=\left(0.25 V_{R d, c, B 4}+A_{s w, t o t} f_{y d} \sin (\alpha)\right) \leq 2 V_{R d, c, B 4} \\
& f_{y d}=\text { design strength of shear reinforcement } \leq 300 \mathrm{MPa}
\end{aligned}
$$

The design tensile strength of concrete $f_{c t d}$ is needed in calculation according to B4. This is calculated as follows:

$$
f_{c t d}=\alpha_{c t} f_{c t k, 0,05} / \gamma_{c}
$$




$$
\begin{aligned}
& \alpha_{c t}=1.0 \\
& f_{c t k, 0,05}=0.7 f_{c t m} \\
& f_{c t m}=0.30 f_{c k}^{2 / 3}, \text { when concrete class } \leq \mathrm{C} 50 / 60
\end{aligned}
$$

This way the design tensile strength as a factor of compressive strength can be expressed as an approximate value, for example for concrete $\mathrm{C} 30 / 37$ as follows:

$$
f_{c t d} \approx 0.045 f_{c k}
$$

It should be mentioned that the Finnish National Annex declares the minimum value for shear strength $v_{\min }=0$. This means that if there is no tensile reinforcement, there is no punching strength either. In the default EC2, the minimum value is defined as:

$$
v_{\min }=0.035 k^{3 / 2} f_{c k}^{1 / 2}
$$

Of course, one must bear in mind that situations where there is absolutely no tensile reinforcement are unrealistic because of minimum reinforcement requirements. Thus, zero punching resistances are purely theoretical when using the Finnish NA.

The maximum increase of punching resistance using shear reinforcement varies between the two methods. The EC2 method has a value of 1.6, defined by the Finnish NA, which is the maximum resistance allowed by using shear reinforcement compared to the value with no shear reinforcement. In the B4 method this value is 2.0, as can be seen from the Equation 14. These maximum resistance increase factors mean that no matter how much shear reinforcement is used, the resulting resistance cannot exceed these values. This is also clearly visible in the comparison charts in Chapter 3. This can be expressed as follows:

$$
\begin{aligned}
& V_{R d, c s, E C 2} \leq 1.6 V_{R d, c, E C 2} \\
& V_{R d, c s, B 4} \leq 2.0 V_{R d, c, B 4}
\end{aligned}
$$

Both methods allow the use of a single line of bent-down bars with an angle of 30 degrees. Only EC2 gives a minimum shear reinforcement equation, which is shown below:

$$
A_{s w, \min } \geq \frac{0.08 \sqrt{f_{c k}} / f_{y k}}{1.5 \sin (\alpha)+\cos (\alpha)} s_{r} S_{t}
$$

The Finnish NA states that when using other than radially placed shear reinforcement, $s_{r} s_{t}$ can be replaced by the total amount of shear reinforcement inside the basic control perimeter $u_{1}$.

\section{COMPARISON SETUPS}

Different setups were chosen to compare results. The following properties apply to all:

- Reinforcement class B500B 
Nordic Concrete Research - Publ. No. NCR 60 - ISSUE 1 / 2019 - Article 8, pp. 131-144

- Square column $380 \mathrm{~mm}$ x $380 \mathrm{~mm}$ (c in Figure 3)

- Distance from reinforcement centre of gravity to the edge of concrete slab was $40 \mathrm{~mm}\left(d_{s}\right.$ in Figure 3)

- Safety factor for concrete $\gamma_{c}=1.5$

- Reduction factor for compressive strength of concrete $\alpha_{c c}=0.85$

- Reduction factor for tensile strength of concrete $\alpha_{c t}=1.00$

- Safety factor for reinforcement $\gamma_{s}=1.15$

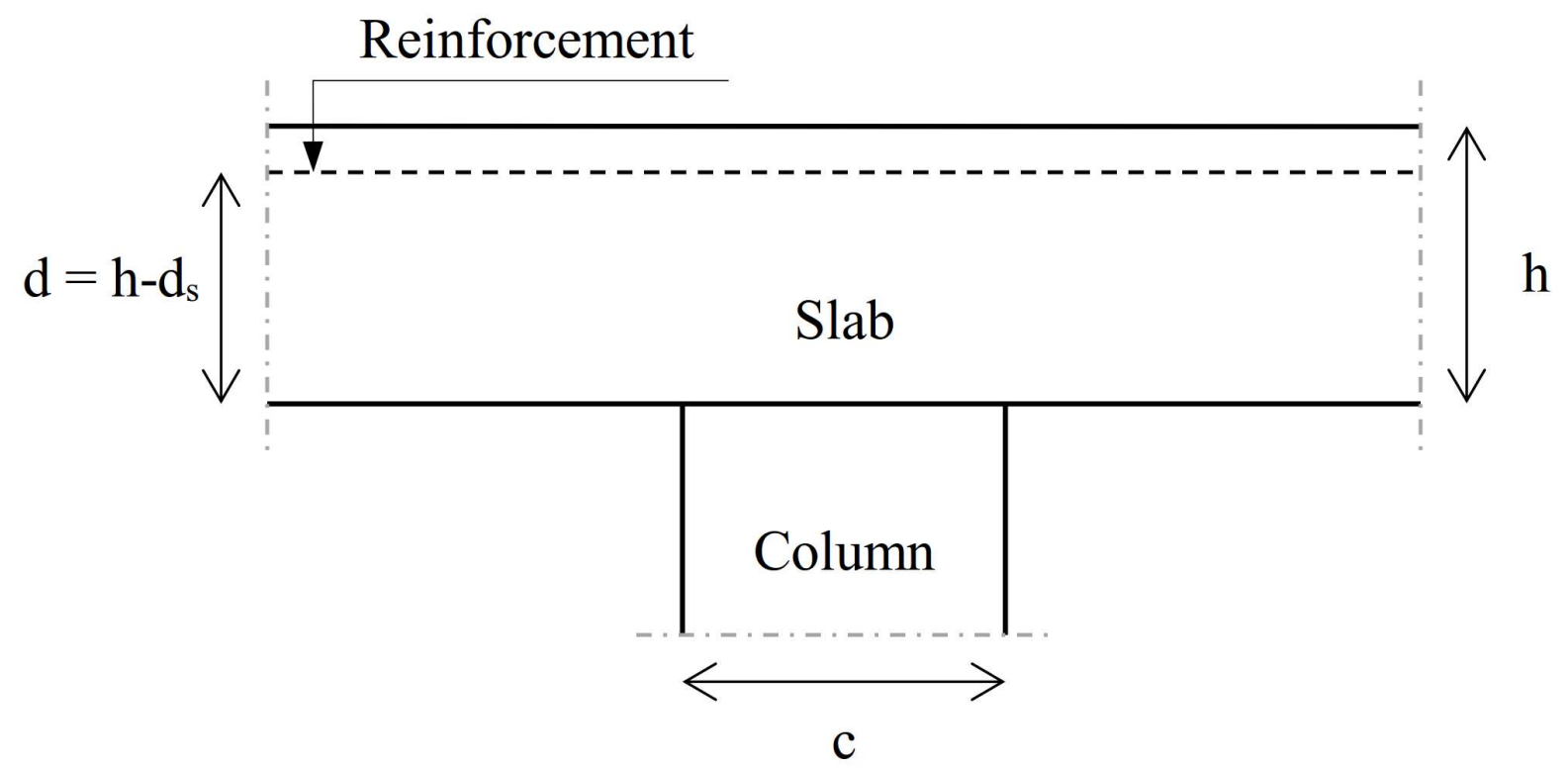

Figure 3 - Schematic representation of the structure.

Punching resistance both with and without shear reinforcement was considered. Bent-down bars with an effective angle of 30 degrees were used in all cases when shear reinforcement was applied. In addition, effect of the eccentricity factor $\beta$ (relating to EC2) was observed as two values: 1.0 and 1.15. This factor takes non-symmetrical shear force distribution into account. The larger the eccentricity of the punching force the lower the punching resistance. Factor $\beta$ increases as the eccentricity increases. 


\subsection{Varying reinforcement ratio (setup \#1)}

The first setup was chosen to represent the effect of slab's reinforcement ratio $\rho$ (ratio between tensile reinforcement area and the product of cross-section width and effective thickness $d$ ) on the punching resistance. Three constant effective thicknesses $d$ (distance from the bottom of the slab to the center-line of effective reinforcement) were adopted, and reinforcement ratio was varied between $1.51 \%$ and $25 \%$. The lower limit represents the minimum reinforcement requirement due to bending and the upper one is chosen to be a bit over the maximum reinforcement ratio of EC2 regarding punching resistance. Eurocode 2 gives a limit value of $20 \%$ after which an increase in reinforcement ratio is no longer effective in increasing punching resistance. Maximum reinforcement ratio in these comparisons is about $18.3 \%$. This represents the maximum amount of reinforcement in the cross-section and should be considered as the realistic upper limit for reinforcement ratios. In usual design situations the ratio is considerably lower than that Thus, all the values of reinforcement ratio above the maximum are purely theoretical and represented only to show how the equations behave further on. No shear reinforcement was involved in this comparison.

\subsection{Varying concrete strength (setup \#2)}

The second setup was chosen to represent the effect of concrete strength $f_{\text {ck }}$ on the punching shear resistance. The related design code equations [1,2], see Equations 1-18, show the concrete strength as a variable is not in same proportion between the two codes. To clarify this notion graphs were plotted with three constant effective thicknesses $d$ and concrete strength was varied between 12 and $50 \mathrm{MPa}$. No shear reinforcement was involved in this comparison. Reinforcement ratio was kept as a constant value of $8 \%$.

\subsection{Varying amount of shear reinforcement (setup \#3)}

The third setup represents how much the applied shear reinforcement affects the punching shear resistance. A single line of bent-down bars with an angle of 30 degrees were chosen as a typical form of shear reinforcement. The total amount of shear reinforcement area passing the punching cone was varied between 0 and $16000 \mathrm{~mm}^{2}$. Reinforcement ratio was kept as a constant value of $8 \%$. 


\section{RESULTS}

Comparison line charts were chosen as the main form of displaying results due to their clarity and versatility. Abbreviations $B 4$ and EC2 relate to the previous Finnish design method and the Eurocode method, respectively. The charts present the punching shear resistance as a single value in kilonewtons taking all the required verifications into account, i.e. maximum compressive stress around the column perimeter $u_{0}$ (length of column periphery).

\subsection{Varying reinforcement ratio (setup \#1)}

Figure 4 illustrates the differences between the two methods. Resistances according to the EC2 method are lower than the B4 method's only with very low reinforcement ratios $\rho$ (around 3\%o). The higher the reinforcement ratio the larger the difference between the two methods.

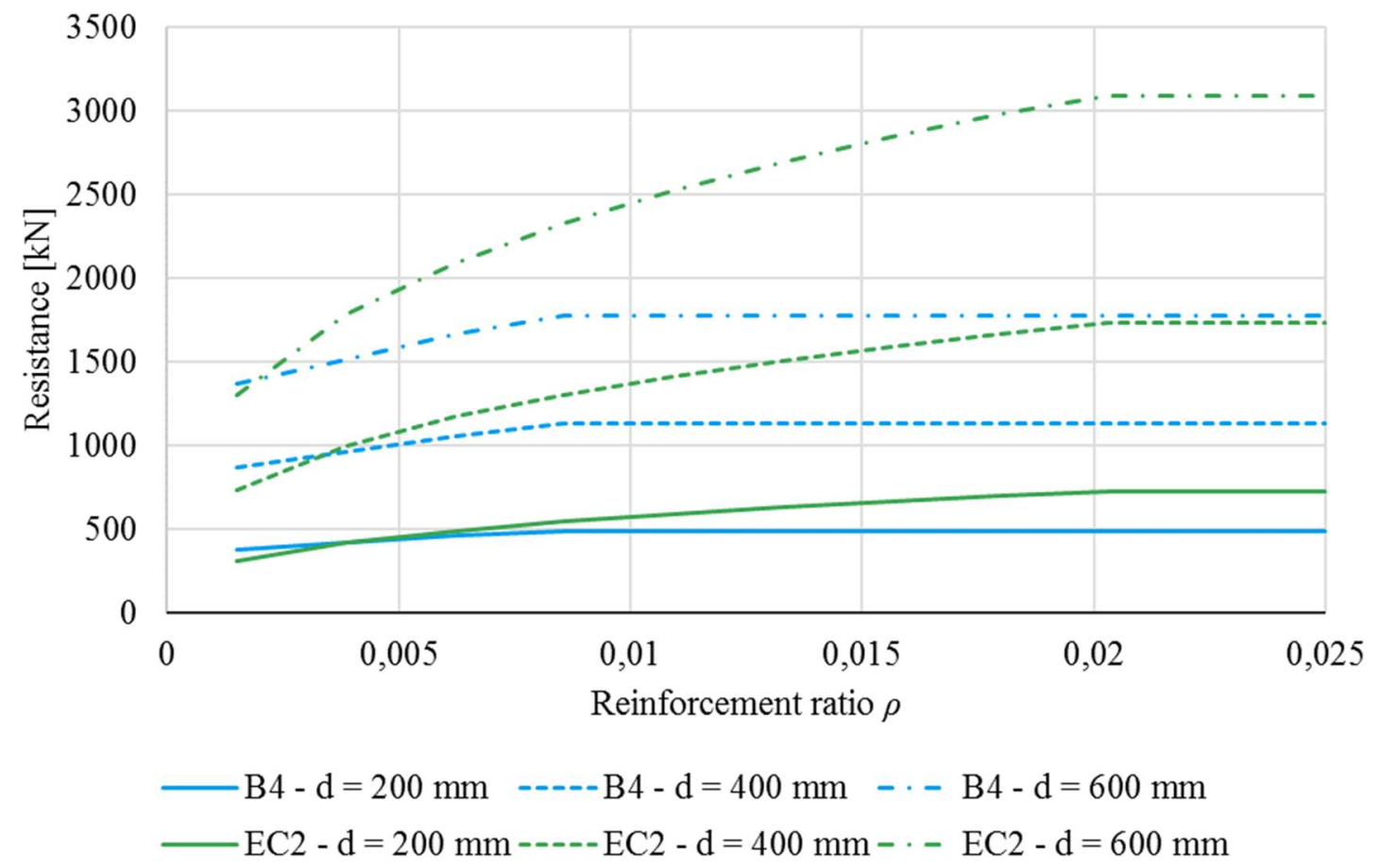

Figure 4-Punching resistance in setup \#1.

Figure 5 further clarifies how large the relative differences are. Relative difference is defined as the remainder of resistances according to EC2 method and B4 method divided by the resistance of B4 method. This results in a positive value when EC2-resistance is higher than B4-resistance, and vice versa, negative values represent situations where B4-resistance exceeds that of the EC2's.

The relative difference increases as effective thickness increases, but nonlinearly. The reason for this behaviour is explained later when dealing with effect of slab thickness on punching resistance, see Section 3.4. 
Nordic Concrete Research - Publ. No. NCR 60 - ISSUE 1 / 2019 - Article 8, pp. 131-144

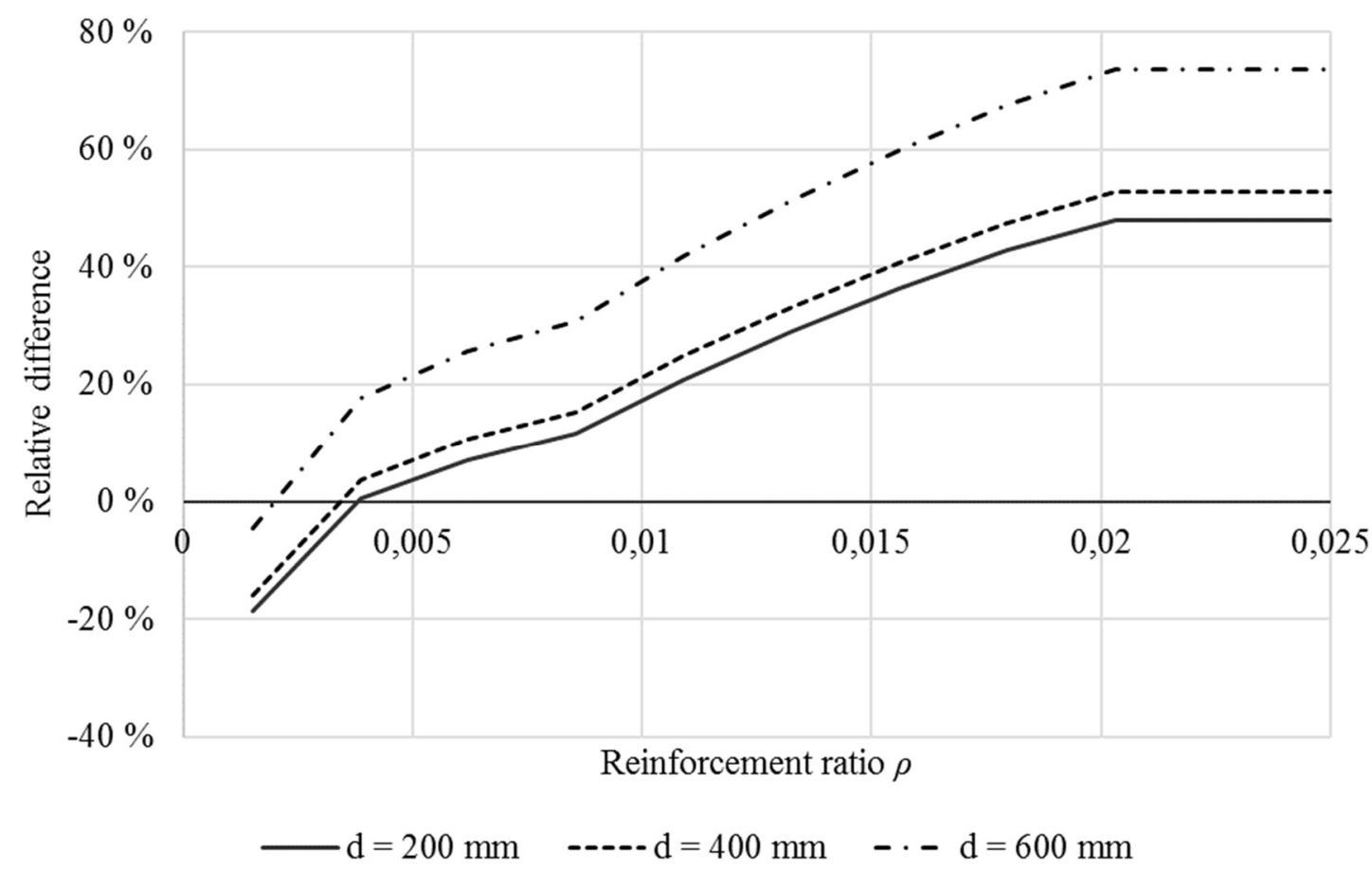

Figure 5 - Relative difference of resistances in setup \#1.

\section{2}

\section{Varying concrete strength (setup \#2)}

Concrete strength plays an important role in punching shear resistance, see Figure 6. It is apparent that the relative difference decreases as the concrete strength increases. In other words, influence of concrete strength seems to be higher in B4 method.

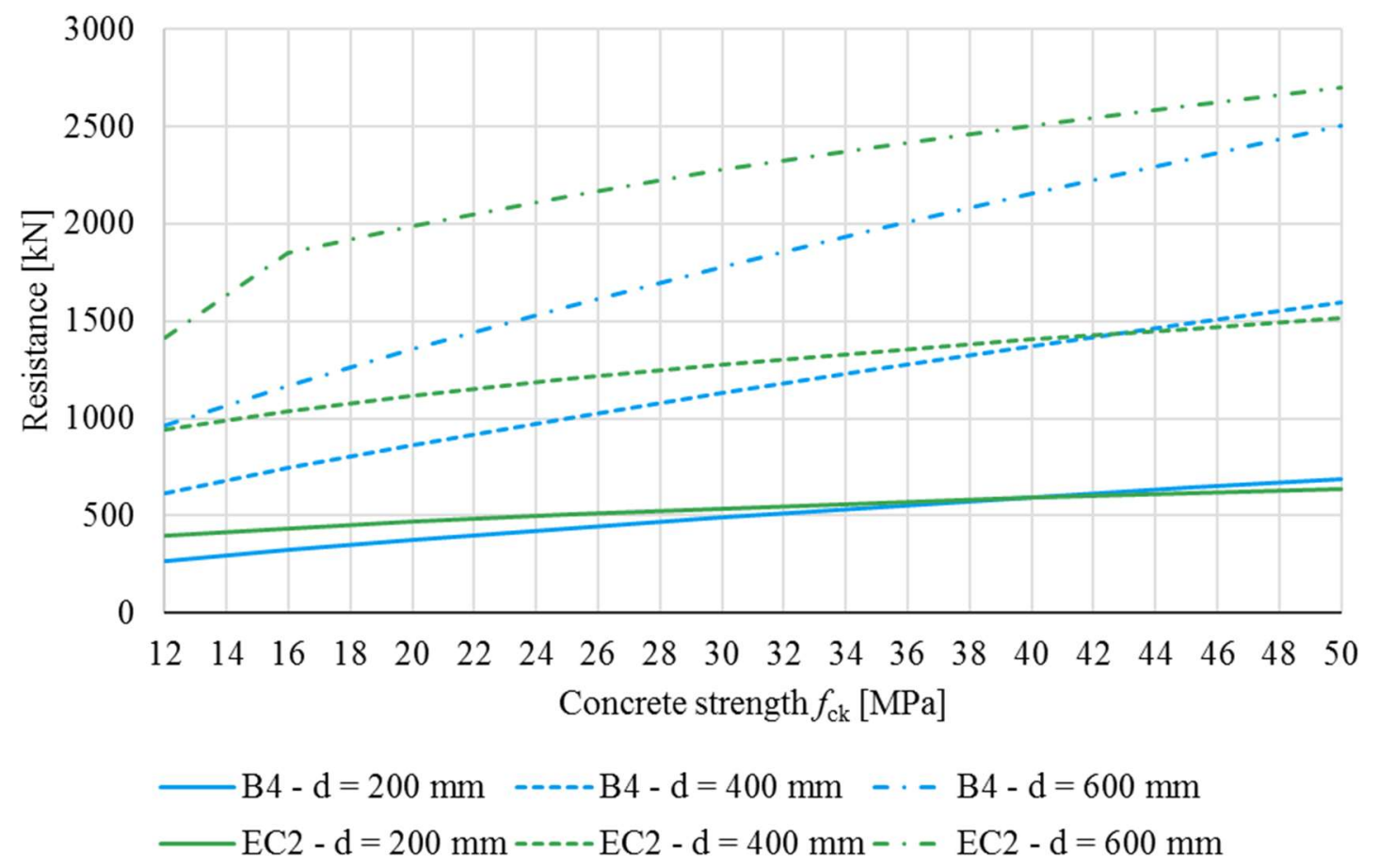


Figure 6-Punching resistance in setup \#2.

The relative difference is at its peak, almost $60 \%$, when examining very low concrete strengths, see Figure 7. Compared to the B4 method, increasing concrete strength in the EC2 method doesn't increase punching resistance relatively as much. The reason for this is found from the design equations: the B4 method has an exponent of $2 / 3$ for $f_{c k}$ whereas EC2 has $1 / 3$. It should be emphasized that concrete strengths $f_{c k}$ below $25 \mathrm{MPa}$ are very low and not used in everyday building design. The graph is constructed to show the differences and the factors affecting the punching resistance.

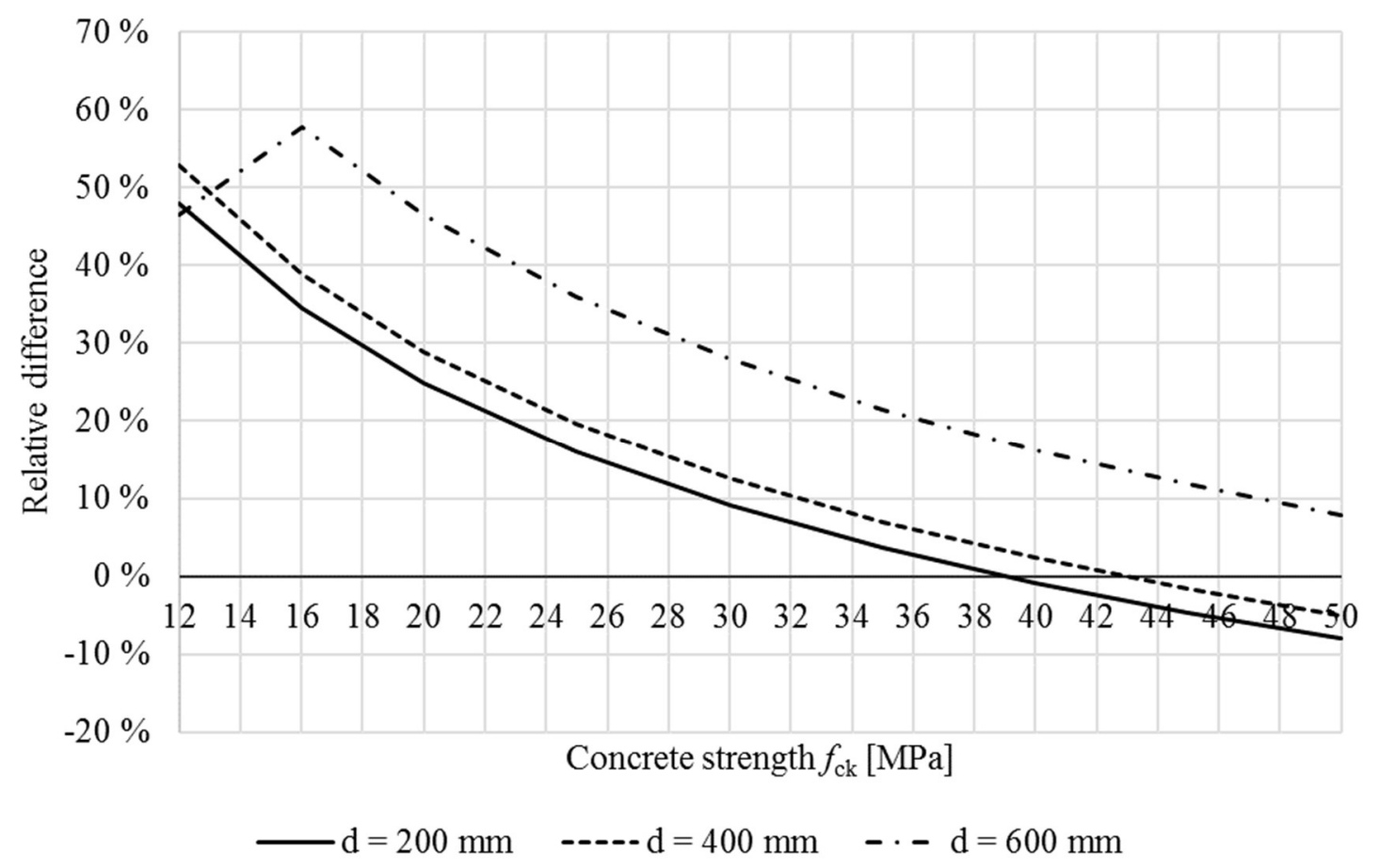

Figure 7 - Relative difference of resistances in setup \#2.

\section{3}

\section{Varying amount of shear reinforcement (setup \#3)}

Figure 8 shows how shear reinforcement affects punching shear resistance. The more shear reinforcement is applied, the higher the punching resistance. Although effective, shear reinforcement influence is limited to a certain amount within design codes. In the B4 method a maximum of two times the resistance of unreinforced (shear reinforcement) slab is allowed, whereas the EC2 method allows only 1,6 as the maximum increase factor. Therefore, the figure below shows only partial incline portions of resistance curves: after the maximum effect is reached, curves plateau.

For all three effective depths $d$ the curve stays horizontal until the minimum amount of shear reinforcement is reached. This is the point where resistance calculated based on shear reinforced structure is higher than that of unreinforced structure. Adding shear reinforcement increases resistance and the slope of the curve displaying this phenomenon seems similar in both methods. 
Nordic Concrete Research - Publ. No. NCR 60 - ISSUE 1 / 2019 - Article 8, pp. 131-144

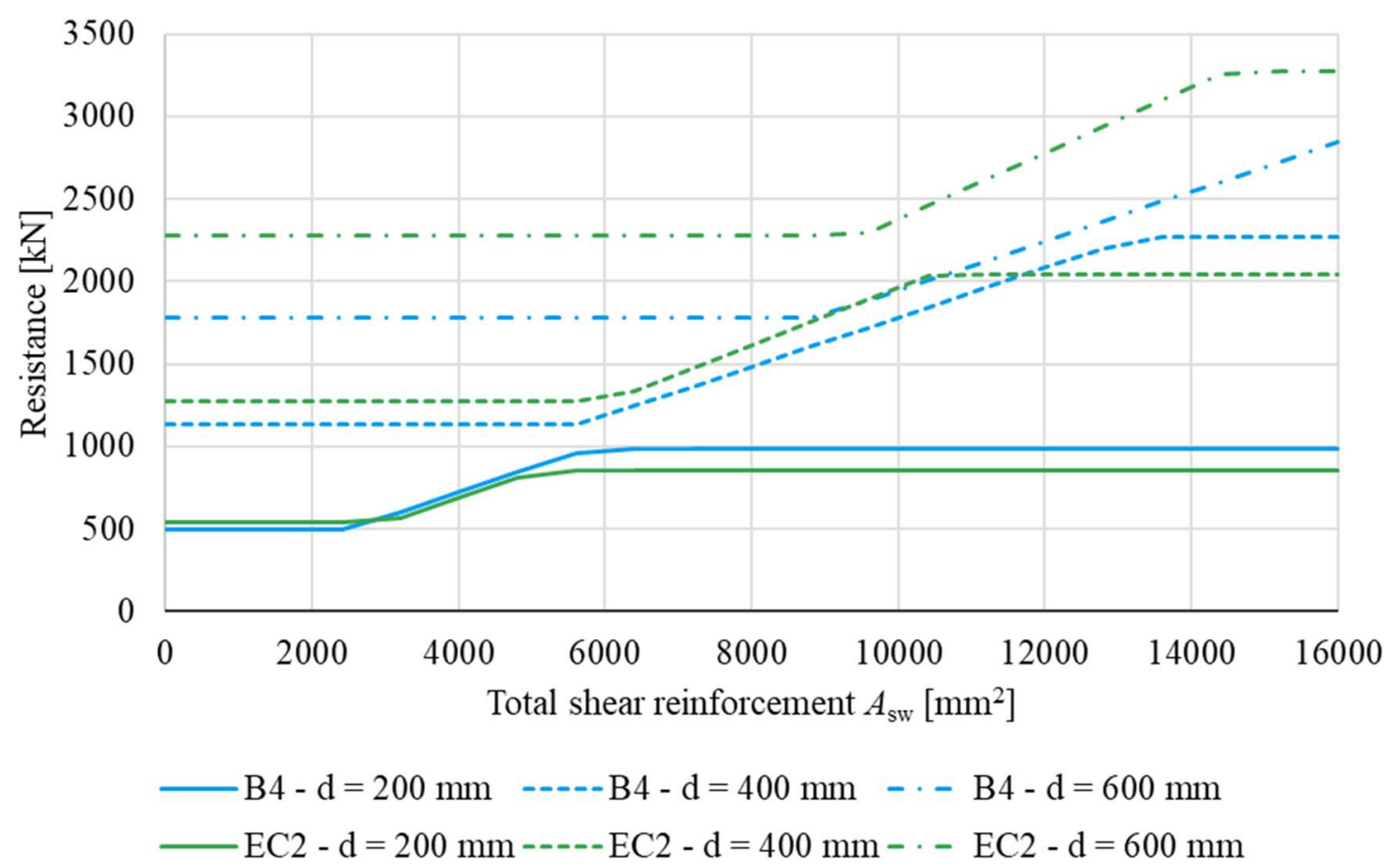

Figure 8-Punching resistance in setup \#3.

Relative differences decrease and switch signs when the area of shear reinforcement increases, see Figure 9. It can be deciphered that the maximum amount of punching shear resistance is higher with the B4 method than the EC2 method.

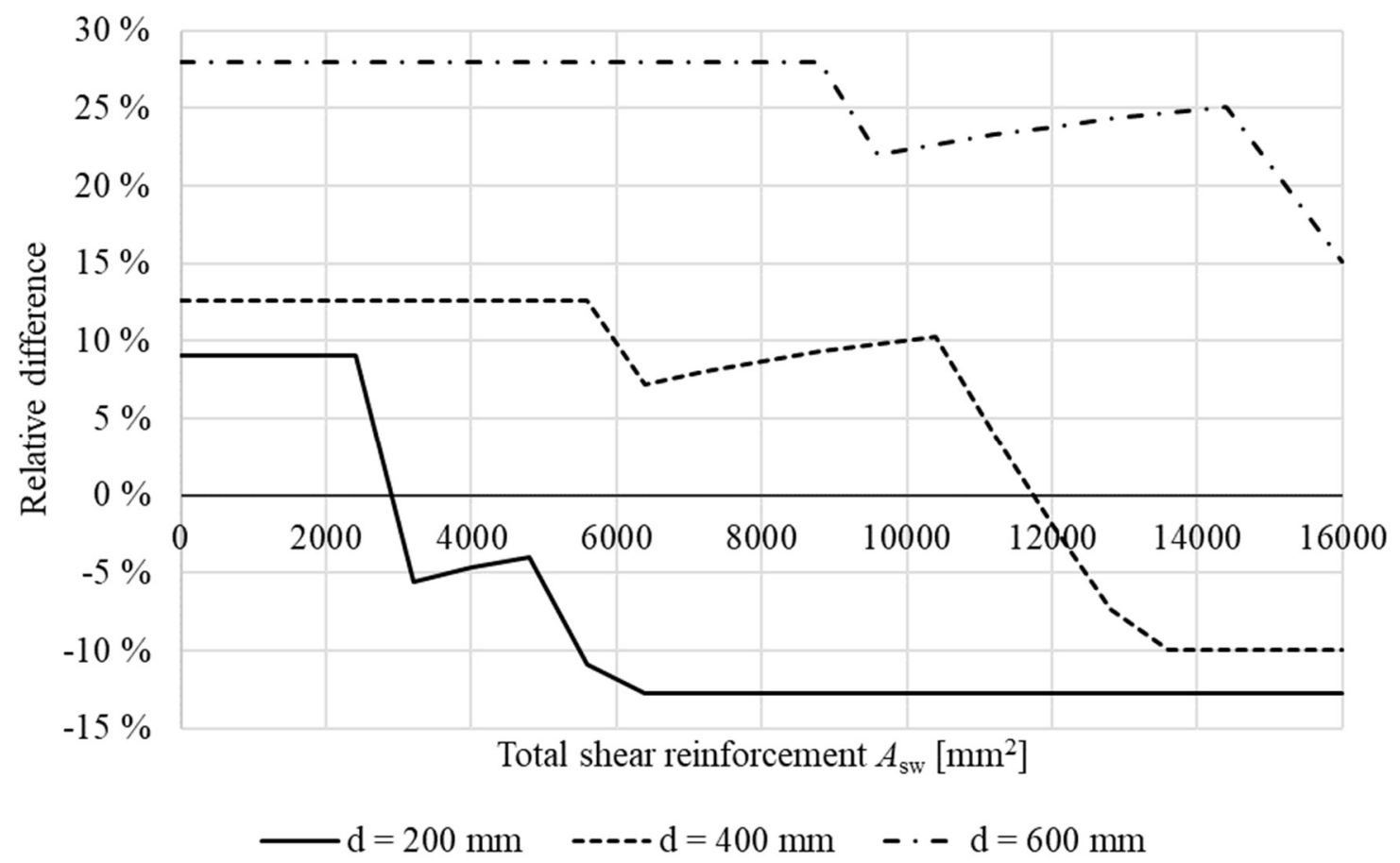

Figure 9-Relative difference of resistances in setup \#3. 
The most notable change in the Finnish national annex in relation the to default Eurocode 2 is the factor $C_{\mathrm{Rd}, \mathrm{c}}$ (coefficient derived from tests affecting shear resistance) which is a constant value in the default EC2 but a variable (considering the effective diameter of the column and the effective slab thickness as factors) in the Finnish NA. This is the most profound difference between the two EC2 methods and constitutes the primary reason why the default EC2 method was forbidden in Finland.

As previous graphs have shown, the EC2 method seems to result in higher resistances than the B4 method as the effective thickness increases. Figure 10 shows how the shape factors $k$ (present in both methods but with different equations) are related to the effective depth. Also control perimeters $u$ are plotted, defined in Equations 6 and 13.

In the absence of axial forces, the punching shear resistance (without shear reinforcement) is directly proportional to the shape factor $k$ and control perimeters $u$ in both. Hence, the slope of the curves in Figure 10 determines how much the punching resistances increase by the increasing effective depth $d$. The factor $k$ ' regarding EC2 means the product of the shape factor $k$ and $C_{R d, c}$. This gives a more accurate form of comparison to method B4.

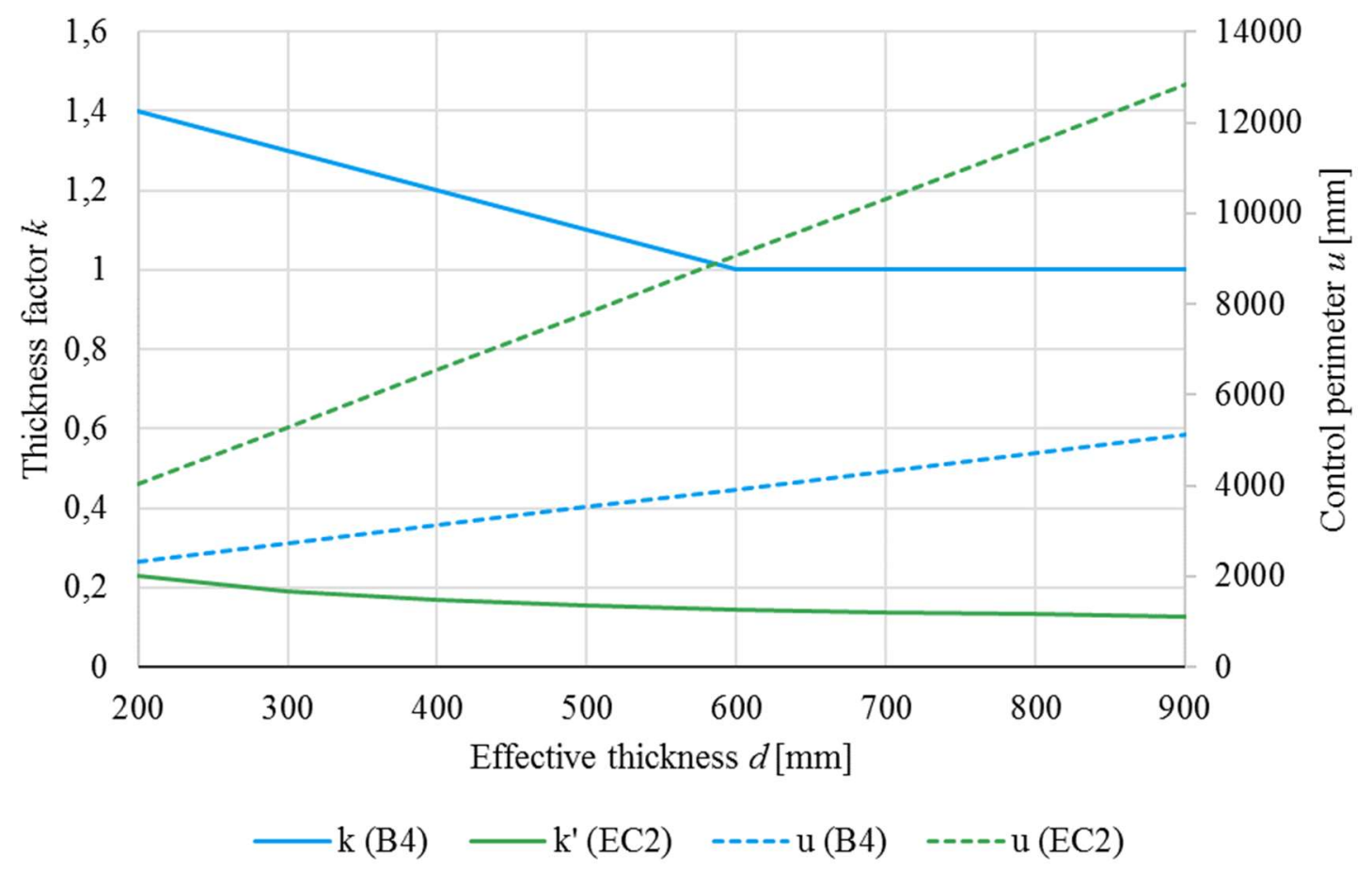

Figure 10 - Effect of thickness factors and control perimeters on punching resistance.

Increasing the effective depth $d$ decreases the shape factor $k^{\prime}$ (EC2) less than $k$ (B4) when $d$ is below $600 \mathrm{~mm}$, after which it remains constant for the B4 method. The control perimeters of the EC2 method increase more than in the B4 method as the effective depth $d$ increases. This can be interpreted such that in general, punching shear resistances according to EC2 increase more than those of the B4 method. In other words, thicker slabs can be utilized more effectively in the EC2 method regarding punching. 


\section{4.}

\section{CONCLUSIONS}

The results in this study demonstrates that the new method implemented in Finland as a national annex for Eurocode 2 gives very different results in some cases compared to the former B4 method. It is worth mentioning that the previous method no longer applies to new building projects in Finland, however bridge design remains to be performed using the B4 method.

According to the new method, higher reinforcement ratios can be utilized with an upper limit of 20\%o whereas with the old B4 method the limit was only 8\%. However, the maximum reinforcement ratio can be lower than $20 \%$, which prohibits the use of such a high amount of reinforcement.

A general conclusion can be made that the new method gives higher punching shear resistances. Slab thicknesses compared to the past are likely to change due to this difference. Concrete compressive strength affects the results significantly: the higher the strength, the smaller the relative difference between the two methods. The two methods weight different variables in the resulting resistance. In short, B4 is more concrete tensile strength oriented whereas EC2 utilizes tensile reinforcement more than B4. It should be noted, that the absolute amount of tensile reinforcement is higher when using EC2 method because the basic control perimeter is longer, and reinforcement must be placed and anchored on a wider area than that of B4's.

The reason for such differences lies behind the complexity of the two design codes. B4 method is more straightforward than EC2 method. The latter has more design equations and is constructed to consider various scenarios and phenomena. It is understandable that simplified methods are usually more conservative than advanced ones, because they must narrow down the variables to be simple enough for everyday use. Despite this, it doesn't mean that advanced methods always produce safe results or are in any way superior to more simple ones.

\subsection{What the future holds}

The second generation of Eurocodes is currently under development and will probably be published around 2022-2024. As in the past, the fib Model Code is a major influencer for the upcoming concrete Eurocode provisions. Drafts of the new EN 1992 have already being published. According to the latest draft [9] shear design will be completely overhauled, and this also concerns punching shear design. The new approach is based on Model Code 2010 [10] and Critical Shear Crack Theory. Basic perimeter will be reduced to $0.5 d$ from the current $2.0 d$ and the whole set of equations are replaced by new ones.

The most important reasons for changing the current default EC2 method are summarized in the background documents [11] for the second generation EC2 as listed below:

- Physical inconsistency with the control perimeter at $2.0 \mathrm{~d}$ and the need for iterative calculation process when dealing with punching shear design of footings,

- The current size effect does not suitably describe the corresponding phenomenon and both underestimate and overestimate the punching resistance in different scenarios,

- The current method includes no slenderness effect, 
- There is both underestimation and overestimation in punching resistance according to experimental tests when shear reinforcement is used.

In general, the background document states that there has been numerous works criticizing different aspects of the current EC2 method. From this it can be deduced that the shortcomings of the current EC2 have been recognized and due to these, the modifications provided by the Finnish National Annex are implemented.

\section{REFERENCES}

1. EN 1992-1-1:2004: "Eurocode 2: Design of concrete structures. Part 1-1: General rules and rules for buildings", European Committee for Standardization, Brussels, Belgium, 2004.

2. The National Building Code of Finland, Part B4: "Concrete structures, regulations and guidelines 2005”. Ministry of the Environment, Helsinki, Finland, 2005.

3. Hirvikoski, M: "The change in punching shear resistance without shear reinforcement according to the new Finnish National Annex to Eurocode 2", B.Sc. Thesis, Tampere University of Technology, Faculty of Business and Built Environment, Laboratory of Civil Engineering, Tampere, Finland, 2017.

4. Rajamäki J: "The change in punching shear resistance with shear reinforcement according to Eurocode 2 with Finnish National Annex", B.Sc. Thesis, Tampere University of Technology, Faculty of Business and Built Environment, Laboratory of Civil Engineering, Tampere, Finland, 2017.

5. Leskelä, M.V.: "EN 1992-1-1: Uusi eurocode 2 standardi betonirakenteiden suunnittelua varten", Rakentajain Kalenteri 2003, Rakennustieto Oy, 2007. (In Finnish).

6. fédération internationale du béton (fib): "Structural Concrete, Volume 2", fib Bulletin 2, Lausanne, Switzerland, 1999.

7. Comité Euro-International du Béton: “CEB-FIP Model Code 1990”. Lausanne, Switzerland, 1993.

8. European Concrete Platform ASBL: "Eurocode 2 Commentary (rev A 31-03-2017)". Brussels, Belgium, 2017.

9. CEN: "prEN1992-1-1:2018: Final Version of PT1-draft prEN 1992-1-1 2018 D3", 2018.

10. fédération internationale du béton (fib): "Model Code 2010 - Final Draft". fib Bulletin 66, Lausanne, Switzerland, 2012.

11. CEN: "Background to prEN 1992-1-1:2018: Background documents to the final PT1 draft prEN 1992-1-1:2018”, 2018. 